\title{
The Use of Zirconium and Feldspathic Porcelain in the Management of the Severely Worn Dentition: A Case Report
}

\author{
Meral Arslan Malkoc \\ Mujde Sevimay \\ Emre Yaprakc
}

\begin{abstract}
The management of the interim phase of a complete oral rehabilitation in patients with severely worn dentition is often challenging due to the loss of occlusal vertical dimension, loss of tooth structure, uneven wear of teeth creating an uneven plane of occlusion, and para-functional habits. This case report describes the management of excessive tooth tissue loss in a 45 year old woman with a history of bruxism, esthetical complaints in anterior teeth, and impaired dental function due to reduced tooth height. The patient used occlusal splint for a month and than resection of the alveolar bone was performed on the vestibular sides of the maxillary anterior teeth, except the interdental alveolar crest. Maxillary anterior teeth were restored with zirconia porcelain. Feldspathic porcelain was chosen to restore remaining teeth in both jaws; the patient also was given an occlusion guard to protect the restoration against future bruxism. Regardless of the cause of occlusal instability, it is important that the restorative dentist should be able to recognize its signs such as tooth hypermobility, tooth wear, periodontal breakdown, occlusal dimpling, stress fractures, exostosis, muscle enlargement, and loss of posterior disclusion. When restoring the worn dentition, the clinician should bear in mind the five P's: proper planning prevents poor performance.
\end{abstract} (Eur J Dent 2009;3:75-80)

Key words: Loss of vertical dimension; Bruxism; Fixed partial restoration; Zirconia; Wear.

- a Research Assistant, Selcuk University, Faculty of Dentistry, Department of Prosthodontics, Konya, Turkey.

${ }^{b}$ Assistant Professor, Selcuk University, Faculty of Dentistry, Department of Prosthodontics, Konya, Turkey.

c Research Assistant, Selcuk University, Faculty of Dentistry, Department of Periodontology, Konya, Turkey.

- Corresponding author: Dr. Mujde Sevimay Selcuk Universitesi, Dishekimligi Fakultesi, Protetik Dis Tedavisi AD. Kampus, Konya, Turkey. Phone: +90 3322231186 Fax: +90 3322410062 E-mail: msevimaylahotmail.com

\section{INTRODUCTION}

The combination of erosion, attrition and abrasion is called tooth wear. Erosion is the loss of hard tissues due to chemical effects, but not bacteria. Attrition is the wear of tooth against tooth and abrasion is the wear of teeth from other surfaces. Recently, the role of abfraction has raised interest into abrasion and the link with attrition but this area is under research. ${ }^{1}$ Extensive tooth wear is considered a potential threat to functional dentition. The management 
of tooth wear, especially from attrition, is becoming a subject of increasing interest in the prosthodontic literature, both from a preventive [how to stop the progress of tooth substance loss (TSL)] and from a restorative point of view lhow to replace the lost tooth substance and to restore function). ${ }^{2}$

By definition, attritional wear is the loss of tooth tissue due to friction between opposing teeth and is thus related to dental occlusion. TSL considered to be normal in aging process, in which depositioning of secondary dentine, alveolar growth, muscle adaptation, and attrition are all parts of a compensation mechanism. ${ }^{2}$

Clinicians are often faced with the challenge of restoring severely worn dentition. A critical aspect for successful treatment of these patients is to determine the occlusal vertical dimension and the interocclusal rest space. A systematic approach to managing this type of complete oral rehabilitation can lead to a predictable and favorable treatment prognosis. ${ }^{3}$

When tooth surface loss is severe, it can be associated with decreased vertical dimension of the occlusion resulting in a poor aesthetic appearance, loss of muscle tone and decreased masticatory efficiency. ${ }^{4}$ In addition, tooth tissue loss from bruxism has been demonstrated to be associated with various dental problems such as tooth sensitivity, excessive reduction of clinical crown height and possible changes of occlusal relationship.

This case report will present a sequence of treatment, including conservative multidisciplinary approach to restoring esthetics and function in a patient with worn anterior dentition.

\section{CASE REPORT}

This case report describes the management of excessive tooth tissue loss in a 45 year old woman with a history of bruxism. Prior to treatment, a detailed dental, medical, and social history was obtained from the patient.

Recent past dental history included only palliative visits during which she had several extractions. She started to notice that her teeth were "getting shorter" about 20 years ago; however, she chose to leave the problem unattended. The patient reported no pain or discomfort. Her goal was to improve the function and esthetics of her dentition. Clinically, the patient demonstrated partial edentulism, several maxillary and mandibular teeth showing severe attrition to the free gingival level, an uneven occlusal plane anteroposteriorly and mediolaterally. Clinically, the patient's facial appearance showed signs of a collapsed occlusal vertical dimension (Figure 1). The preoperative interocclusal rest space was $3 \mathrm{~mm}$. Periodontal condition and soft-tissue examination showed no pocket depth of over $2 \mathrm{~mm}$ or mobility of any remaining teeth. Radiographic evaluation demonstrated excellent bone support for the remaining teeth. The patient's maxilla diagnosed with Class II Div 1 and mandibula Class III Div 1 according to the Kennedy classification system for partial edentulism (Figure 1).

\section{Prosthodontic management}

The findings were explained to the patient, and treatment options were presented. The treatment goals were to restore the lost occlusal vertical dimension (OVD) to correct the occlusal plane, to

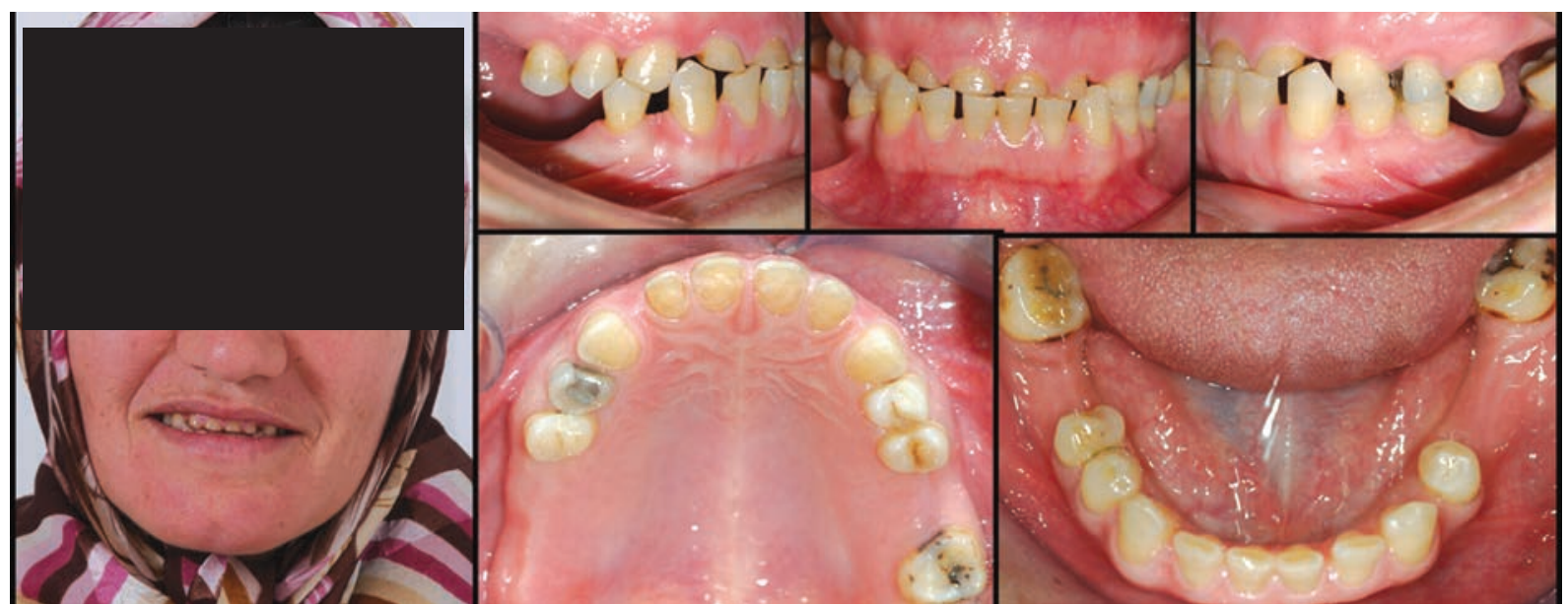

Figure 1. Pretreatment facial and intraoral photographs. 
restore function, and to restore the esthetics of the patient's dentition.

The treatment consisted of a phased treatment plan. Phase I included a splint therapy and a provisional fixed prosthesis to re-establish correct vertical dimension of occlusion and stable occlusal contacts. The patient used the occlusal splint (Figure 2) for a month. TMJ and muscle examinations were done at the first week and at the first month. Phase II treatment included surgical crown lengthening. Surgical crown lengthening was a proposed procedure to provide additional restorative retention. This procedure should only be considered when the remaining root is supported by a healthy periodontium and the post-surgery crown/root ratio will be favorable. In the clinical examination there was no sign of gingival inflammation or periodontal infection, or tooth mobility. In the periapical radiographic examination, root/crown ratio of the teeth were more than two, and there was no alveolar resorption. Sulcular and internal bevel incisions were performed with preserving the gingival papillas, without any vertical incisions. Because there was an adequate amount of attached gingiva, internal bevel incision was performed 3-4 $\mathrm{mm}$ far away from the gingival margin, considering the zenith points in the anterior maxilla. After the removal of remnant gingiva, full-thickness muco-periosteal flap elevated. Approximately, 3-4 $\mathrm{mm}$ of marginal alveolar bone was resected. Interdental bone

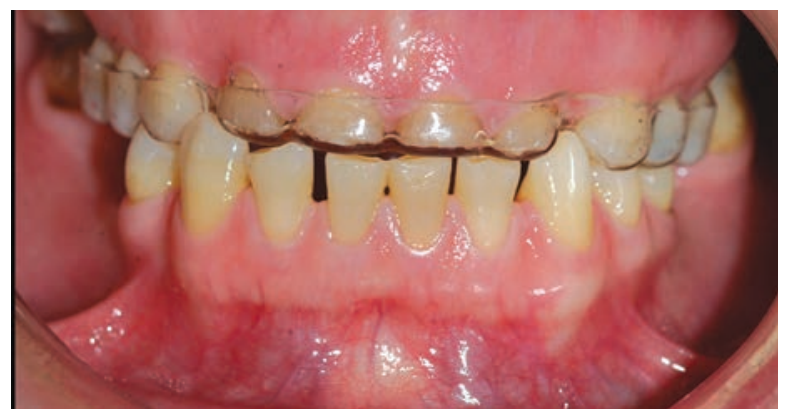

was not resected. Flap was closed using nylon sutures with vertical matrix suture technique. And also frenulum attachment was removed by frenectomy operation. The sutures were removed at the first week after the surgery. Wound healing was completed at the $6^{\text {th }}$ week after the surgery in the follow-up period (Figure 3).

After healing, the patient was scheduled for tooth preparation. The design of the tooth preparation should encompass necessary reduction relative to tooth position and the requirements of the restorative material. The abutment teeth (\#11,\#12, \#13, \#21, \#22, \#23) for zirconium restorations were prepared, which implied a 1.2-mm deep circumferential shoulder and a slightly rounded inner angle. ${ }^{5,6}$

The other abutment teeth (\#14, \#15, \#24, \#25, \#27, \#33, \#34, \#37, \#43, \#44, \#45, \#47) were prepared with a knife edge finish line (Figure 4). Impressions for the maxillary and mandibular interim prostheses were made using a vinyl polysiloxane impression (Elite HD, Zhermak, Germanyl material. The impression was cast with a type IV dental stone (Silky-Rock; Whip Mix Corp, Louisville, Kyl, and the stone cast was mounted in a semi adjustable articulator (Dentatus ARHtype; Dentatus AB, Stockholm, Sweden) with an opposing mandibular cast. Feldspathic porcelain was chosen to restore other teeth in both jaws; the patient also was given an occlusion guard to protect the restoration against future bruxism. Definitive restorations were evaluated, adjusted for optimal contacts, contours, and esthetics. The crowns were luted with self-polymerizing composite resin cement (Multilink, Ivoclar Vivadent, Schaan, Liechtenstein) (Figure 5). After prosthetic management, the patient was instructed about individual oral hygiene care of fixed prostheses.

After insertion of the interim prostheses the patient reported no muscular or

Figure 2. Occlusal splint.

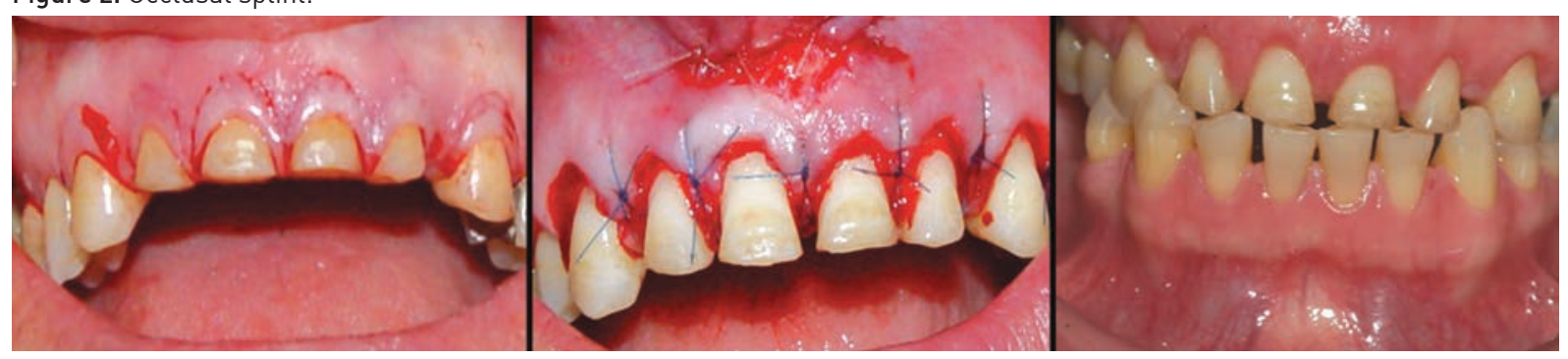

Figure 3. Periodontal surgery and wound healing at the follow-up period. 
temporomandibular joint discomfort. The patient was also placed in a maintenance recall program. Follow-up treatments were done to evaluate the patient's comfort, arch form, and potential occlusal vertical dimension problems. Patient was recalled twice for postoperative examinations during a 1-year follow-up period (Figure 6). In the controls it was seen that marginal adaptation of the prostheses was appropriate and there were no signs of gingival inflammation and recession.

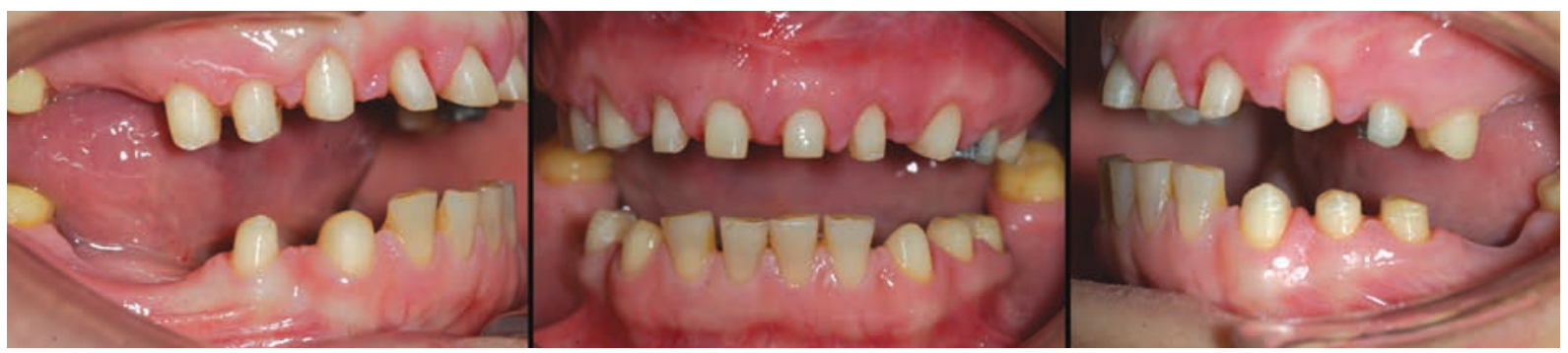

Figure 4. Preparation of teeth.

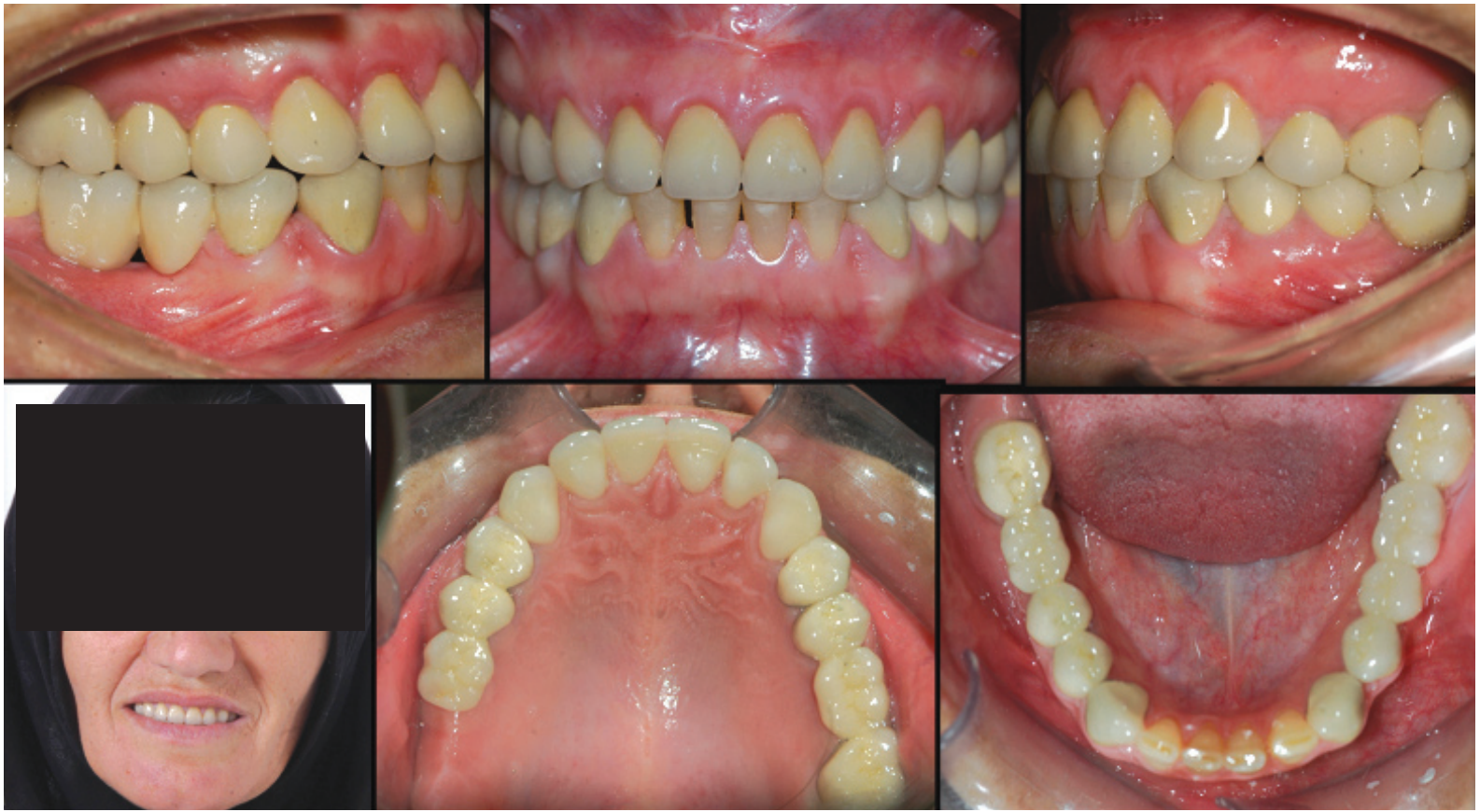

Figure 5. Post treatment photographs.

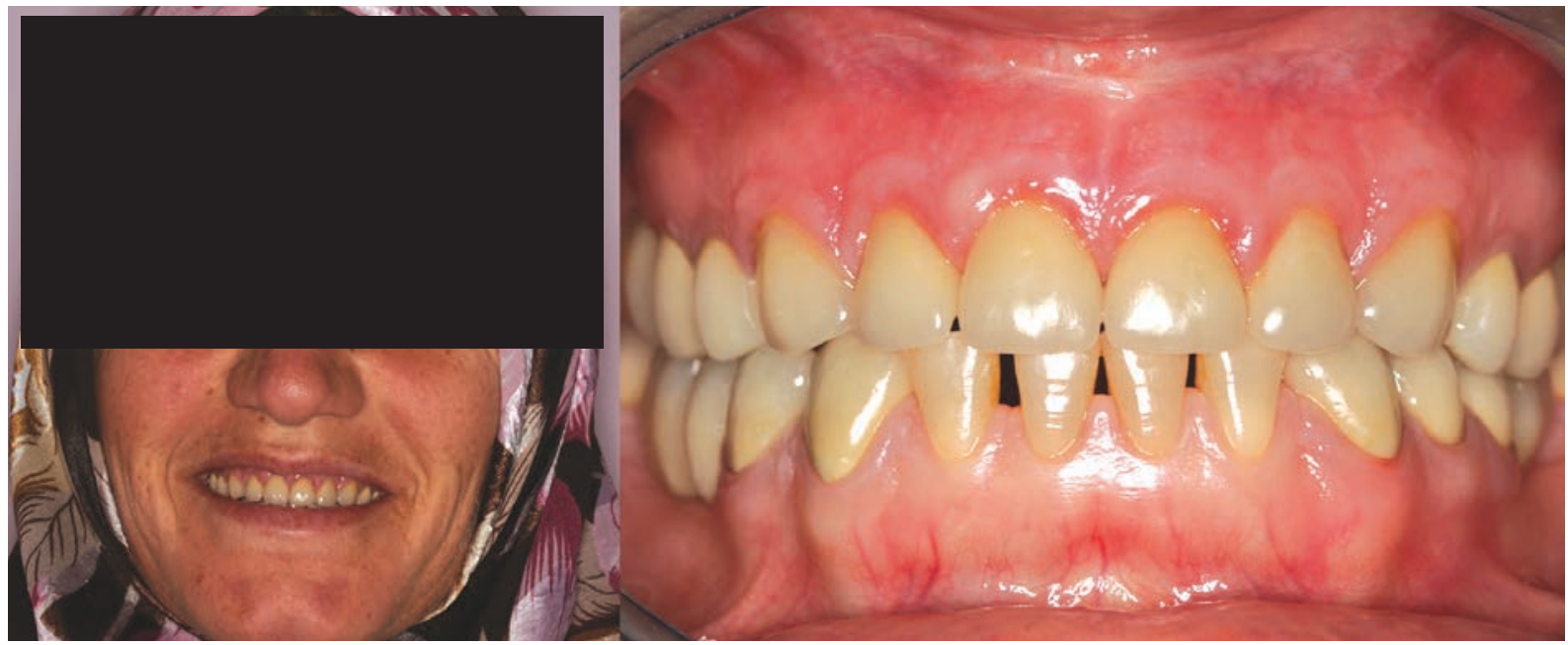

Figure 6. Extraoral view of the patient and intraoral view of the restorations after 1 year. 


\section{DISCUSSION}

The etiology of occlusal wear for our patient is not fully understood; however, it can be hypothesized that the patient had a parafunctional occlusal habit and started grinding her anterior teeth. Once the anterior teeth got shorter, the patient lost anterior guidance and developed posterior interferences. The posterior interferences in lateral excursions can activate the masseter and temporalis muscles, enabling the patient to generate more forces to grind her teeth more aggressively. ${ }^{7}$ A mutually protected occlusal scheme was used to prevent the destruction of the new prostheses. ${ }^{3}$

Mutually protected articulation is described as "an occlusal scheme in which the posterior teeth prevent excessive contact of the anterior teeth in maximum intercuspation, and the anterior teeth disengage the posterior teeth in all mandibular excursive movements." Studies have shown that in lateral excursive movements, ${ }^{8}$ the anterior teeth can best receive and dissipate the forces 9 and posterior contacts in excursions appear to provide unfavorable forces to the masticatory system because of the amount and direction of the applied forces. ${ }^{10,11}$ In addition to the use of the mutually protected occlusal scheme, an occlusal splint was fabricated for night wear, and the patient was instructed and trained to keep her teeth apart when not actively chewing. Zirconia ceramic crowns were selected for the patient's treatment to ensure adequate strength on upper anterior teeth. The primary advantage of a zirconia restoration is esthetic benefit, as it is translucent and tooth-colored. ${ }^{12} \mathrm{~A}$ metal-free ceramic crown can transmit a great amount of incident light through to a ceramic core where light is scattered in a natural fashion. ${ }^{12}$ Thus, the appearance of definitive restorations may be very close to that of a natural tooth.

Many factors influence the choice of allceramic systems for abraded upper incisors. Strength, fit, and esthetics are traditionally considered in the selection of material for full coverage restorations. Anterior crowns can be fixed to the tooth by traditional cements or resin cements. Traditional cements occupy the space between the restoration and the tooth surfaces but do not provide adhesion between them. Resin cements provide adhesion to both surfaces and can act to transfer force from the restoration to the underlying tooth and strengthen all-ceramic restorations. ${ }^{13}$ Also resin cement was used to provide additional bonding strength to increase the retention of the restorations because our patient's clinical crown was not long enough.

In the present case, the maxillary occlusal plane had already been established. Therefore it was relatively straightforward to restore the occlusion to a new vertical dimension. The use of a provisional occlusal splint is generally considered the first step in the treatment of inappropriate horizontal and vertical maxillomandibular relationships.

In the present case, approximately $4 \mathrm{~mm}$ of crown lengthening was obtained in the maxillary anterior teeth by resective bone surgery. Some studies suggested that patients with healthy periodontium have $0.69 \mathrm{~mm}$ mean sulcus depth, $0.97 \mathrm{~mm}$ epithelial attachment and $1.07 \mathrm{~mm}$ connective tissue. ${ }^{14}$ Therefore the total length of supracreasteal gingival tissue was $2.73 \mathrm{~mm}$. So, reconstitution of $2.73 \mathrm{~mm}$ of gingival tissue must be considered, while deciding the amount of bone resection. ${ }^{15}$ Protection sufficient amount of attached gingiva around the teeth after the surgery is also an important task to achieve. ${ }^{16}$ In our case, $5 \mathrm{~mm}$ of attached gingiva existed after the surgery. In order to prevent the frenulum become high after the surgery, frenectomy operation also performed at the same appointment.

\section{CONCLUSIONS}

In the present case report, it has been shown that, after the use of occlusal guard and the surgical treatment; restoration of maxillary teeth with full coverage restorations and mandibular teeth with metal-ceramic restorations help to restore the occlusal vertical dimension. Dentists have the responsibility of developing proper form and function to protect the integrity of the masticator system, and must connect the new materials and technology with traditional functional concepts to be successful. As the case presented here demonstrates, this combination of innovation and tradition is achievable with careful planning. The restored occlusal vertical dimension has shown to be physiologically and esthetically acceptable to the patient. 


\section{REFERENCES}

1. Bartlett D. The implication of laboratory research on tooth wear and erosion. Oral Diseases 2005;11:3-6.

2. van 't Spijker A, Kreulen CM, Creugers NH. Attrition, occlusion, (dys)function, and intervention: a systematic review. Clin Oral Implants Res 2007;18(Suppl 3):117-126.

3. Phuhong DD, Goldstein GR. The use of a diagnostic matrix in the management of the severely worn occlusion. $J$ Prosthodont 2007;16:277-281.

4. Guttal S, Patil NP. Cast titanium overlay denture for a geriatric patient with a reduced vertical dimension. Gerodontology 2005;22:242-245.

5. Steyern PY, Carlson P, Nilner K. All-ceramic fixed partial dentures designed according to the DC-Zirkon technique. A 2-year clinical study. J Oral Rehabil 2005;32:180-187.

6. Komine F, Iwai T, Kobayashi K, Matsumura H. Marginal and internal adaptation of zirconium dioxide ceramic copings and crowns with different finish line designs. Dent Mater $J$ 2007;26:659-664.

7. Williamson EH, Lundquist DO. Anterior guidance: its effect on electromyographic activity of the temporal and masseter muscles. J Prosthet Dent 1983;49:816-823.

8. The Glossary Of Prosthodontic Terms. 8th Edition. J Prosthet Dent 2005;94:10-92.

9. Standlee JP, Caputo AA, Ralph JP: Stress transfer to the mandible during anterior guidance and group function eccentric movements. J Prosthet Dent 1979;41:35-39.

10. Ramfjord SP: Dysfunctional temporomandibular joint and muscle pain. J Prosthet Dent 1961;11:353-374.

11. Manns A, Miralles R, Valdivia J, Bull R. Influence of variation in anteroposterior occlusal contacts on electromyographic activity. J Prosthet Dent 1989;61:617-623.

12. Koutayas SO, Kern M. All-ceramic posts and cores: the state of the art. Quintessence Int 1999;30:383-392.

13. Hsu KW, Shen YF. Esthetic restoration of infra-occluded retained primary mandibular incisors with all-ceramic crowns in adult dentition. Chang Gung Med J 2004;27:911917

14. Gargiulo AW, Wentz F, Orban B. Dimensions and relations of the dentogingival junction in humans. $J$ Periodontol $1961 ; 32: 261-267$.

15. Lanning SK, Waldrop TC, Gunsolley JC, Maynard JG. Surgical crown lengthening: evaluation of the biological width. J Periodontol 2003;74:468-474.

16. Wang HL, Greenwell H. Surgical periodontal therapy. Periodontol 2000 2001;25:89-99. 